\title{
Effect of Bacteroides fragilis cellular components on chemotactic activity of polymorphonuclear leukocytes towards Escherichia coli
}

\author{
F. NAMAVAR, A. M. J.J. VERWEIJ-VAN VUGHT, M. BAL and D. M. MACLAREN
}

Department of Medical Microbiology, Research Group for Commensal Infections, Vrije Universiteit, Van der Boechorststraat 7, 1081 BT Amsterdam, The Netherlands

\begin{abstract}
Summary. Chemotaxis of polymorphonuclear leukocytes (PMNL) in response to cell components of Bacteroides fragilis alone or in combination with Escherichia coli was evaluated. $E$. coli produced much more powerful chemotactic factors than $B$. fragilis. The culture filtrate (CF), outer membrane (OM) preparation, and lipopolysaccharide (LPS) of $B$. fragilis slightly stimulated chemotactic activity of PMNL. The culture filtrate and OM preparation were capable of inhibiting the chemotaxis of PMNL in response to the chemotactic factors of $E$. coli but LPS of $B$. fragilis was not able to do so. Reduction by $B$. fragilis of PMNL chemotaxis in response to $E$. coli was not specific for $B$. fragilis but also occurred in the presence of facultative bacteria. In parallel with chemotaxis, lysozyme release, but not $\beta$-glucuronidase release, by PMNL was significantly stimulated by $E$. coli but not by $B$. fragilis.
\end{abstract}

\section{Introduction}

Clinical and experimental observations of infections in which Bacteroides spp. are involved have led to the conclusion that bacteroides infections are characterised by abscess formation. $B$. fragilis is often associated in mixed infections with aerobic bacteria and often seems to play a key role in their pathogenesis, since its elimination by prophylactic chemotherapy prevents the establishment of infection (Hofstad and Kristofferson, 1970; Gorbach and Bartlett, 1974). Recent work has shown that anaerobic bacteria inhibit the phagocytosis and killing of aerobic bacteria (Ingham et al., 1977; Jones and Gemmell, 1982; Namavar et al., 1983; Connolly et al., 1984; Vel et al., 1985). Much work has been done to determine possible virulence factors of $\boldsymbol{B}$. fragilis. This micro-organism produces lipopolysaccharide (LPS) with low biological toxicity (Kasper, 1976; Sveen et al., 1977) and also a capsular polysaccharide (Kasper and Seiler, 1975) whose role in virulence is still controversial (MacLaren et al., 1984). Inhibition of chemotaxis might be an important virulence factor in the early stages of $B$. fragilis infection; the development of abcesses suggests that it does not play a significant role in the later stages.

Received 14 Aug. 1986, accepted 6 Oct. 1986
In our previous study (Namavar et al., 1984), we found that the culture filtrates (CF) of $B$. fragilis inhibited polymorphonuclear leukocyte (PMNL) chemotaxis stimulated by Proteus mirabilis. Showell et al. (1976) and Becker (1976) have demonstrated the release of granule enzymes from cytochalasin B-treated PMNL exposed to synthetic chemotactic peptides, and found a close correlation between the ability of chemotactic stimuli to cause enzyme release and migration.

In this study, we report the chemotactic and antichemotactic effects of CF, outer membrane (OM) preparations and LPS of $B$. fragilis on the chemotactic stimulus of Escherichia coli. The effects of CF of $B$. fragilis, E. coli and a synthetic peptide upon exocytosis of PMNL were tested. Specificity of chemotaxis inhibition by $B$. fragilis on $E$. coli was tested with culture filtrates of Staphylococcus aureus and Klebsiella pneumoniae instead of $B$. fragilis.

\section{Materials and methods}

\section{Bacterial strains}

The strains used in these experiments were $E$. coli $\mathrm{EB} 1$ (serotype $\mathrm{O8} \mathrm{K43)}$ and $B$. fragilis BE1. Both strains were isolated from a mixed aerobic-anaerobic wound infection. In some experiments $S$. aureus NCTC 6571 and a clinical isolate of $K$. pneumoniae, $52 \mathrm{~K} 2$, were used. 


\section{Media}

The BM broth (Shah et al., 1976) normally used for the growth of Bacteroides spp. was itself chemotactic for human PMNL. Therefore, to assess the chemotactic response of PMNL towards bacteria, a non-stimulating medium was used which had previously been described for measuring the chemiluminescence response of leukocytes (Namavar et al., 1983). This was the minimal medium of Varel and Bryant (1974) for growth of $B$. fragilis.

\section{Preparation of culture filtrates and cell suspension}

B. fragilis BE1 was incubated for $24 \mathrm{~h}$ at $37^{\circ} \mathrm{C}$ in an anaerobic chamber in an atmosphere of $\mathrm{N}_{2}, 85 \%, \mathrm{H}_{2}$ $10 \%, \mathrm{CO}_{2} 5 \%$. Facultative bacteria were incubated in the same medium at $37^{\circ} \mathrm{C}$ in a waterbath with shaking. The numbers of anaerobic and facultative bacteria were determined by optical density and adjusted to $10^{9} \mathrm{cfu} / \mathrm{ml}$. Culture filtrates were prepared by centrifugation $(1300 \mathrm{~g}$, $15 \mathrm{~min}, 4^{\circ} \mathrm{C}$ ) and filter sterilised through $0.45-\mu \mathrm{m}$ membrane filters (Millipore). Cells were washed twice in phosphate-buffered saline (PBS) and resuspended in control medium to a concentration of $10^{9} \mathrm{cfu} / \mathrm{ml}$.

\section{Preparation of LPS and OM}

LPS was extracted from $B$. fragilis BE1 by a modified Westphal procedure (Keleti and Lederer, 1974). LPS was assayed for protein by Bio-Rad protein assay (Bio-Rad Laboratories B.V., The Netherlands) with bovine plasma albumin as a standard. The LPS contained $2 \%$ protein. The $\mathrm{OM}$ of the $B$. fragilis was isolated by the method of Kasper and Seiler (1975). In this study the OM was the crude material isolated by centrifugation at $80000 \mathrm{~g}$ at $4^{\circ} \mathrm{C}$ for $2 \mathrm{~h}$; this was suspended in a minimal volume of distilled water and lyophilised. The OM preparation contained $25 \%$ protein.

\section{Preparation of PMNL}

PMNL were separated from heparinised blood of healthy adults by dextran sedimentation. They were washed once in TC medium 199 (Difco) containing $2 \mathrm{mM}$ $\mathrm{L}$-glutamine and resuspended in the same medium at a concentration of $10^{7} \mathrm{PMNL} / \mathrm{ml}$. The $p \mathrm{H}$ of the medium was adjusted to $7 \cdot 4$ with $\mathrm{NaHCO}_{3} 7 \cdot 5 \%$ w/v solution.

\section{Chemotactic assay}

The chemotaxis of PMNL was determined by the agarose chemotactic assay as previously described (Namavar et al., 1984). The media contained agarose $1.2 \%$ $\mathrm{w} / \mathrm{v}, 10 \mathrm{ml}$ of $10 \times \mathrm{TC}$ medium $199,1 \mathrm{ml}$ of sodium bicarbonate $7.5 \% \mathrm{w} / \mathrm{v}, 10 \mathrm{ml}$ of inactivated new-born calf serum and $79 \mathrm{ml}$ of distilled water. A $10-\mathrm{ml}$ volume of the agarose medium was delivered into each tissue culture plate $(60 \times 15 \mathrm{~mm}$; No. 3002 , Falcon, CA, USA). Four series of three wells, $3 \mathrm{~mm}$ in diameter and $3 \mathrm{~mm}$ apart were made in the agarose gel. The centre well of each three-well series received $10 \mu \mathrm{l}$ of PMNL suspension $\left(10^{7} / \mathrm{ml}\right)$, the outer well $10 \mu \mathrm{l}$ of chemotactic factor and the inner well $10 \mu \mathrm{l}$ of control medium. The plates were incubated at $37^{\circ} \mathrm{C}$ in a humidified atmosphere containing $\mathrm{CO}_{2} 5 \%$ in air. After incubation for $3 \mathrm{~h}$ the plates were flooded with $5 \mathrm{ml}$ of methanol for $30 \mathrm{~min}$ and then with formalin $4 \%$ for $30 \mathrm{~min}$. The agarose was removed and the cells stained with Wright's stain. Each migration figure was magnified 25 times under a microscope and chemotaxis was measured by subtracting the spontaneous migration from the directed migration. The chemotaxis of the CF of $E$. coli was considered to be $100 \%$.

\section{Induced lysosomal enzyme release}

A $0.5-\mathrm{ml}$ volume of washed PMNL $\left(10^{7} / \mathrm{ml}\right)$ was preincubated for $10 \mathrm{~min}$ at $37^{\circ} \mathrm{C}$ with or without $0.5 \mathrm{ml}$ of cytochalasin B (CB) $10 \mu \mathrm{g} / \mathrm{ml}$. The CB was diluted in control medium from a stock solution containing $\mathrm{CB}$ $5 \mathrm{mg} / \mathrm{ml}$ in dimethyl sulphoxide. The dimethyl sulphoxide remaining after dilution was shown not to effect enzyme release (Showell et al., 1976). In duplicate, $0.5 \mathrm{ml}$ of cell suspension was added to $0.5 \mathrm{ml}$ of CF of EB1, BEl or $10^{-7} \mathrm{M} \quad \mathrm{N}$-formyl-methionyl-leucyl-phenylalanine $(\mathrm{F}$ Met-Leu-Phe, Sigma Chemical Co., St. Louis, MO, USA). The mixture was then incubated for $10 \mathrm{~min}$ at $37^{\circ} \mathrm{C}$ and the tubes centrifuged at $1500 \mathrm{~g}$ for $5 \mathrm{~min}$ at $4^{\circ} \mathrm{C}$. The CF was removed and samples taken for measurements of lysozyme and $\beta$-glucuronidase. The $\beta$-glucuronidase was measured with the substrate 4-nitrophenyl glucuronide (Boehringer Mannheim GMbH). Lysosyme was determined by the rate of lysis of Micrococcus luteus measured bydecreaseinabsorbanceat $450 \mathrm{~nm}$ (Boehringer Mannheim, 1981).

\section{Statistical analysis}

Statistical analysis of the data was by analysis of variance and Student's $t$-test.

\section{Results}

\section{Chemotactic factors of $B$. fragilis and $E$. coli.}

The mean chemotactic activities of the PMNL from 10 different healthy donors, when stimulated by the CF and washed cells of $E$. coli and $B$. fragilis, are compared in fig. 1. Washed cells and CF of $E$. coli each induced chemotaxis equally. Chemotactic factors produced by $E$. coli were a property of viable cells because heat killed $\left(30 \mathrm{~min}, 70^{\circ} \mathrm{C}\right)$ cells did not produce chemotactic factors. Chemotactic factors were, however, heat stable because heattreated CF did not show a significant difference in chemotactic stimulation from the unheated CF. The washed cells and CF of $E$. coli contained more 


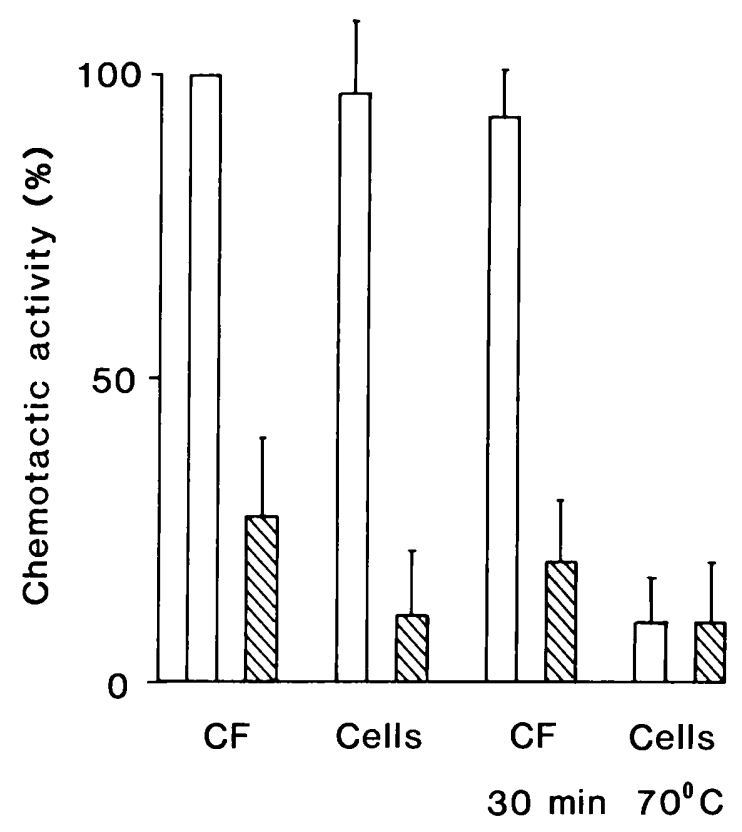

Fig. 1. Chemotactic activity of PMNL induced by $\mathrm{CF}, \mathrm{CF}$ heated for $30 \mathrm{~min}$ at $70^{\circ} \mathrm{C}$, viable cells and killed cells $(30 \mathrm{~min}$, $70^{\circ} \mathrm{C}$ ) of $E$. coli $\mathrm{EB} 1(\square)$ and $B$. fragilis BE1 (ब). Values expressed as mean of 10 experiments; bars represents ISD.

powerful chemotactic factors than those of $B$. fragilis.

\section{Induction of chemotaxis by LPS and OM}

The LPS and OM preparation of $B$. fragilis BE1 were assayed at various concentrations to measure possible chemotactic activity for PMNL (fig. 2).

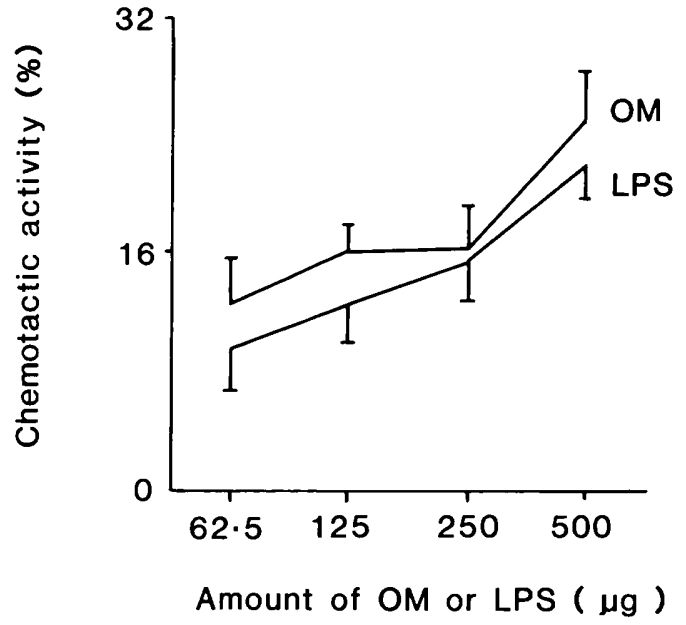

Fig. 2. Dose response of PMNL to $B$. fragilis BE1 OM and LPS. Values expressed as mean percentages of five experiments; bars represent $1 \mathrm{SD}$.

LPS and OM of $B$. fragilis slightly stimulated chemotactic activity of PMNL. A proportional increase in chemotaxis was observed with increasing amounts of LPS and OM. Chemotactic stimulus by $500 \mu \mathrm{g}$ of the OM preparation of $B$. fragilis BE1 $(25 \pm 4 \cdot 1)$ was almost the same as by CF $(28 \pm 3 \cdot 8)$.

Effect of E. coli and B. fragilis on lysosomal enzyme release

Table 1 shows the effects of chemotactic factors on lysosomal enzyme release from PMNL. In the absence of CB, PMNL did not show significant differences in $\beta$-glucuronidase release when stimu-

Table I. Lysosomal enzyme release from PMNL, untreated and treated with cytochalasin B (CB).

\begin{tabular}{|c|c|c|c|c|}
\hline \multirow[b]{3}{*}{ Added factors } & \multicolumn{4}{|c|}{ Enzyme release (units/ml) (SD)* } \\
\hline & \multicolumn{2}{|c|}{ lysozyme } & \multicolumn{2}{|c|}{$\beta$-glucuronidase } \\
\hline & without $\mathrm{CB}$ & with CB & without CB & with CB \\
\hline Control medium & $115(13)$ & $188(57)$ & $1.9(0 \cdot 8)$ & $2 \cdot 1(0 \cdot 3)$ \\
\hline Culture filtrate: & & & & \\
\hline E. coli & $244(43) \dagger$ & $390(56) \dagger$ & $2 \cdot 8(0 \cdot 7) \ddagger$ & $4.0(0.6) \dagger$ \\
\hline B. fragilis & $160(48) \dagger$ & $225(35) \dagger$. & $2.4(0.8) \ddagger$ & $3 \cdot 2(0 \cdot 7) \dagger$ \\
\hline f-Met-Leu-Phe, $10^{-7} \mathrm{M}$ & $194(14) \dagger$ & $519(84) \dagger$ & $2 \cdot 7(0 \cdot 8) \ddagger$ & $3.9(1.0) \dagger$ \\
\hline
\end{tabular}

* Values expressed as mean (SD) of five experiments.

$\dagger \mathrm{p}<0.05$, significantly larger than control medium.

$\ddagger \mathrm{p}>0.05$, not significant. 
lated with CF of $E$. coli or B. fragilis, or $10^{-7} \mathrm{M}$ f-Met-Leu-Phe. However, the three chemotactic factors significantly stimulated $\beta$-glucuronidase release from CB-treated PMNL $(\mathrm{p}<0 \cdot 05)$. No significant differences were found in $\beta$-glucuronidase release between the three chemotactic factors. In the absence of $\mathrm{CB}$, all three chemotactic factors stimulated significantly more lysozyme release than did the control medium $(\mathrm{p}<0.05)$ but the differences between $E$. coli, $B$. fragilis and $10^{-7} \mathrm{M}$ f-Met-LeuPhe preparations were not significant. Cytochalasin B-treated PMNL showed a significant increase in lysozyme release with all chemotactic factors in comparison with the control medium. The chemotactic peptide f-Met-Leu-Phe stimulated significantly more lysozyme release than $E$. coli $\mathrm{CF}$, and $E$. coli CF significantly more than $B$. fragilis CF (p $<0.05)$.

\section{Induction of chemotaxis by combination of E. coli $C F$, and B. fragilis cells, subcellular components or $C F$}

The CF of $B$. fragilis significantly reduced the chemotactic activity of PMNL towards $E$. coli (fig. 3) (p <0.05). The effects of combining $E$. coli $C F$ with the OM, LPS or CF of $B$. fragilis on the chemotactic activity of PMNL are shown in table II. The LPS preparation, up to a concentration of $500 \mu \mathrm{g}$, had no significant effect on the chemotactic stimulus of $E$. coli CF. However, $125 \mu \mathrm{g}$ of crude

Table II. Effect of $B$. fragilis cell components on chemotactic activity of PMNL towards $E$. coli $C F$.

Reaction mixture Index of chemotactic activity

\begin{tabular}{ll} 
E. coli + control medium $\dagger$ & \multicolumn{1}{c}{100} \\
E. coli + B. fragilis LPS: & \\
$500 \mu \mathrm{g}$ & $86(10 \cdot 0)$ \\
$250 \mu \mathrm{g}$ & $88(6 \cdot 2)$ \\
$125 \mu \mathrm{g}$ & $94(6 \cdot 7)$ \\
E. coli + B. fragilis $\mathrm{OM}:$ & \\
$500 \mu \mathrm{g}$ & $71(9 \cdot 4) \ddagger$ \\
$250 \mu \mathrm{g}$ & $74(10 \cdot 0) \ddagger$ \\
$125 \mu \mathrm{g}$ & $77(6 \cdot 8) \ddagger$ \\
$62 \cdot 5 \mu \mathrm{g}$ & $88(10 \cdot 9)$ \\
E. coli + B. fragilis CF $\dagger$ & $75(10 \cdot 7) \ddagger$
\end{tabular}

\footnotetext{
* Values expressed as mean percentages of control values (SD) \pm standard deviation of five experiments.

$\dagger \mathrm{CF}$ of $E$. coli diluted 1 in 2 in control medium or B. fragilis CF. $\ddagger \mathrm{p}<0.05$, significantly lower than control value.
}

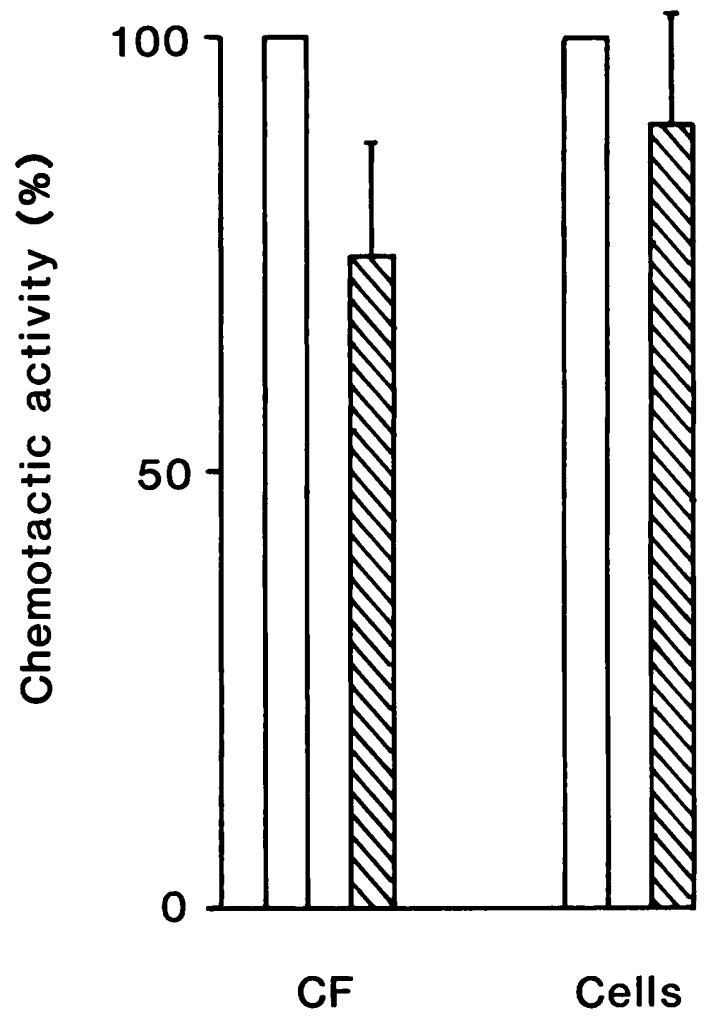

Fig. 3. Chemotactic activity of PMNL induced by CF and washed cells of $E$. coli $\mathrm{EB} 1$ alone, or in combination with $\mathrm{CF}$ and washed cells of $B$. fragilis BE1. The CF or washed-cell preparations of $E$. coli were diluted 1 in 2 in control medium ( $\square$ ) or in the CF or washed cells of $B$. fragilis $(\mathbb{D})$. Values were expressed as mean percentages of 10 experiments; bars represents ISD.

OM significantly reduced ( $\mathrm{p}<0.05$ ) the chemotactic activity of PMNL towards $E$. coli $C F$. These results suggest that the inhibitory effect of $B$. fragilis BE1 on chemotactic activity of PMNL towards $E$. coli can be caused by CF and OM.

\section{Specificity of chemotaxis inhibition by $B$. fragilis}

To assess the specificity of the effect of $B$. fragilis CF on chemotaxis of PMNL by $E$. coli, these experiments were repeated with $S$. aureus NCTC 6571 and $K$. pneumoniae 52K2 culture filtrates instead of $B$. fragilis CF (fig. 4). In the same conditions as described in fig. 3, the chemotaxis of PMNL to E. coli $C F$ was significantly reduced ( $\mathrm{p}<$ 0.05 ). These findings indicate that reduction by $B$. fragilis of PMNL chemotaxis towards $E$. coli was not specific for $B$. fragilis but also occurs in the presence of facultative bacteria. 


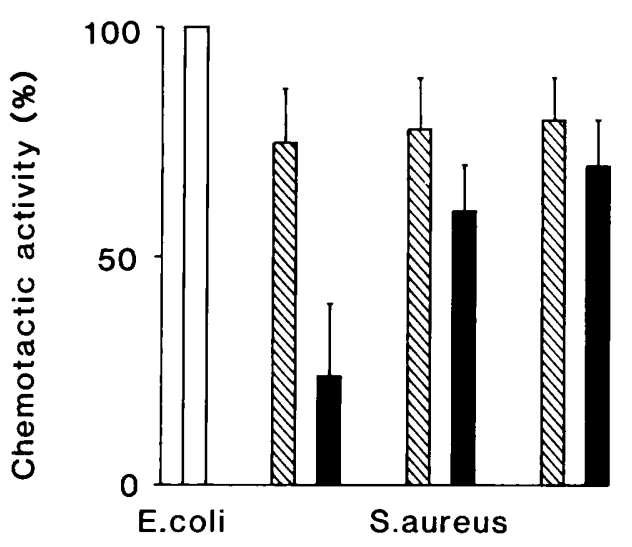

B.fragilis K.pneumoniae

Fig. 4. Chemotactic activity of PMNL induced by CF of $E$. coli $(\square), B$. fragilis, S. aureus and $K$. pneumoniae ( $\square)$. The CF of $E$. coli was also diluted 1 in 2 in the CF preparations of $B$. fragilis and of the facultative bacteria $(\mathbb{\mathbb { S }})$. Values are expressed as mean percentages of 10 experiments; bars represent $1 \mathrm{SD}$.

\section{Discussion}

In our previous studies we found that $E$. coli strain EB1 was killed by PMNL when normal serum was present. However, B. fragilis strain BEl was not only killed but also significantly inhibited the killing of E. coli (Vel et al., 1985). Pathogenic synergy was also observed when these two strains were tested in mice (Verweij-van Vught et al., 1985). The aim of the present study was to evaluate how these two strains alone or in combination affected the chemotaxis of PMNL. The chemotaxisinducing factors of $E$. coli EB1 were extracellular, heat stable and potent. Only slight to moderate chemotaxis was induced by the LPS, OM and CF of $B$. fragilis BE1.

These observations are in keeping with the results of Adamu and Sperry (1981). Because there are reports (Becker and Showell, 1974; Showell et al., 1976) indicating that chemotactic stimuli, such as chemotactic peptides, stimulate enzyme release from human and rabbit neutrophils, we evaluated the effect of CF of $E$. coli and B. fragilis and the chemotactic peptide f-Met-Leu-Phe on lysosomal enzyme release from human leukocytes. Smith et al. (1980) have reported that chemotactic peptides stimulate enzyme release from human PMNL in the presence, but not in the absence, of the CB. Cytochalasin B is believed to curtail such PMNL activities as phagocytosis by interfering with contractile microfilament function (Davis et al., 1971). The microfilamentous system is located below the cell membrane and may restrain lysosomal granules from fusing with the plasma mem- brane, which would abrogate the extracellular release of granulase-associated enzyme. Cytochalasin B, however, by curtailing this restraining effect of microfilaments would facilitate the interaction of cell membrane and cytoplasmic granules. In the absence of $\mathrm{CB}$, we found that lysosomal enzyme release was similar whichever chemotactic factors were used.

The amount of lysozyme release exceeded the amount of $\beta$-glucuronidase in all conditions. In parallel with its effect upon chemotaxis, the supernate of $E$. coli stimulated significantly more lysozyme release than the $B$. fragilis supernate but not more $\beta$-glucuronidase release.

The CF of $B$. fragilis significantly inhibited the chemotactic response of PMNL to $E$. coli. This antichemotactic activity was found in the OM and the CF preparations of $B$. fragilis but not in the LPS component. We did not test the effect of the OM on serum complement, but other investigators have shown that components of OM preparations of $B$. fragilis react with serum complement to inhibit locomotion of PMNL (Adamu and Sperry, 1981). The inhibiting effect of $B$. fragilis CF on chemotaxis of PMNL by $E$. coli was non-specific. The CF of $S$. aureus and $K$. pneumoniae also significantly inhibited the chemotaxis of PMNL towards $E$. coli. Nonspecificity of the effect of $B$. fragilis on phagocytosis and killing of $E$. coli by PMNL also has been reported (Vel et al., 1985; Wade et al., 1983). It seems, therefore, that $\boldsymbol{B}$. fragilis does not stimulate a particularly strong PMNL chemotactic response when compared with $E$. coli.

Kasper (1976) has reported the lack of local Schwartzman phenomena in rabbits to concentrations of $B$. fragilis endotoxin and OM of up to $1 \mathrm{mg}$ per rabbit. $B$. fragilis LPS and OM also failed to kill 10-day-old chick embryos in doses up to $200 \mu \mathrm{g} / \mathrm{egg}$.

Wade et al. (1983) have found no deleterious effect by the capsular polysaccharide of $B$. fragilis on chemotaxis by PMNL. In some preliminary experiments we studied in-vivo chemotaxis of $B$. fragilis $\mathrm{BE} 1$ and $E$. coli $\mathrm{EB} 1$ and Proteus mirabilis in subcutaneously implanted poly-allomer chamber in guinea-pigs by the method of Veale et al. (1974). The results of these experiments showed that $E$. coli and $P$. mirabilis culture filtrates strongly stimulated the accumulation of PMNL into the chambers after $6 \mathrm{~h}$, but $B$. fragilis culture filtrate did not (unpublished data). Therefore, it is possible that $B$. fragilis avoids early contact with the PMNL by inhibiting chemotaxis of PMNL for long enough to allow sufficient growth of $\boldsymbol{B}$. fragilis and accompanying facultative bacteria eventually to overwhelm phagocytosis and establish infection. 


\section{REFERENCES}

Adamu S A, Sperry J F 1981 Polymorphonuclear neutrophil chemotaxis induced and inhibited by Bacteroides spp. Infection and Immunity 33: 806-810.

Becker E L, Showell H J 1974 The ability of chemotactic factors to induce lysosomal enzyme release. 2 The mechanism of release. Journal of Immunology 112: 2055-2062.

Becker E L 1976 Some interrelations of neutrophil chemotaxis, lysosomal enzyme secretion, and phagocytosis as revealed by synthetic peptides. American Journal of Pathology 85: 385-394.

Boehringer Mannheim Co. 1981 Biochemical information. Boehringer Mannheim Co., Biochemica, West Germany.

Connolly J C, McLean C Tabaqchali S 1984 The effect of capsular polysaccharide and lipopolysaccharide of Bacteroides fragilis on polymorph function and serum killing. Journal of Medical Microbiology 17: 259-271.

Davis A T, Estensen R, Quie P G 1971 Cytochalasin B.3. Inhibition of human polymorphonuclear leukocyte phagocytosis. Proceedings of the Society for Experimental Biology and Medicine 137: 161-164.

Gorbach S L, Bartlett J G 1974 Anaerobic infections. New England Journal of Medicine 290: 1177-1184, 1237-1245, 1289-1294.

Hofstad T, Kristoffersen T 1970 Chemical characteristics of endotoxin from Bacteroides fragilis NCTC 9343. Journal of General Microbiology 61 : 15-19.

Ingham H R, Sisson P R, Tharagonnet D, Selkon J B, Codd A 1977 Inhibition of phagocytosis in vitro by obligate anaerobes. Lancet 2: 1252-1254.

Jones G R, Gemmell C G 1982 Impairment by Bacteroides species of opsonisation and phagocytosis of enterobacteria. Journal of Medical Microbiology 15: 351-361.

Kasper D L, Seiler M W 1975 Immunochemical characterization of the outer membrane complex of Bacteroides fragilis subspecies fragilis, Journal of Infectious Diseases 132: 440450.

Kasper D L 1976 Chemical and biological characterization of the lipopolysaccharide of Bacteroides fragilis subspecies fragilis. Journal of Infectious Diseases 134: 59-66.

Keleti G, Lederer W H 1974 Handbook of micro-methods for the biological sciences. Van Nostrand-Reinhold Co., New York, pp. 3-4, 31-32.

MacLaren D M, Namavar F, Verweij-van Vught A M J J, Vel W A C Kaan J A 1984 Pathogenic synergy: mixed intraabdominal infections. Antonie van Leeuwenhoek 50: 775787.
Namavar F, Verweij-van Vught A M J J, Bal M, van Steenbergen T J M, de Graaff J, MacLaren D M 1983 Effect of anaerobic bacteria on killing of Proteus mirabilis by human polymorphonuclear leukocytes. Infection and Immunity 40: 930-935.

Namavar F, Verweij-van Vught A M J J, Vel W A C, Bal M, MacLaren D M 1984 Polymorphonuclear leukocyte chemotaxis by mixed anaerobic and aerobic bacteria. Journal of Medical Microbiology 18: 167-172.

Shah H N, Williams R A D, Bowden G H, Hardie J M 1976 Comparison of the biochemical properties of Bacteroides melaninogenicus from human dental plaque and other sites. Journal of Applied Bacteriology 41 : 473-492.

Showell H J et al. 1976 The structure-activity relations of synthetic peptides as chemotactic factors and inducers of lysosomal enzyme secretion for neutrophils. Journal of Experimental Medicine 143: 1154-1169.

Smith R, Wierenga W, Iden S S 1980 Characteristics of $\mathrm{N}$ formyl-methionyl-leucyl-phenylalanine as an inducer of lysosomal enzyme release from human neutrophils. Inflammation 4: 73-88.

Sveen K, Hofstad T, Milner K C 1977 Lethality for mice and chick embryos, pyrogenicity in rabbits, and ability to gelate lysate from amoebocytes from Limulus polyphemus by lipopolysaccharides from Bacteroides, Fusobacterium and Veillonella. Acta Pathologica et Microbiologica Scandinavica Section B 85: 388-396.

Varel V H, Bryant M P 1974 Nutritional features of Bacteroides fragilis subsp. fragilis. Applied Microbiology 18: 251-257.

Veale D R, Smith H, Witt K A, Marshall R B 1974 Differential ability of colonial types of Neisseria gonorrhoeae to produce infection and an inflammatory response in sub-cutaneous perforated plastic chambers in Guinea-pigs and rabbits. Journal of Medical Microbiology 8: 325-335.

Vel W A C, Namavar F, Verweij-van Vught A M J J, Pubben A N B, MacLaren D M 1985 Killing of Escherichia coli by human polymorphonuclear leucocytes in the presence of Bacteroides fragilis. Journal of Clinical Pathology 38: 86-91.

Verweij-van Vught A M J J, Namavar F, Sparrius M, Vel W A C, MacLaren D M 1985 Pathogenic synergy between Escherichia coli and Bacteroides fragilis: studies in an experimental mouse model. Journal of Medical Microbiology 19: 325-331.

Wade B H, Kasper D L, Mandell G L 1983 Interactions of Bacteroides fragilis and phagocytes: studies with whole organisms, purified capsular polysaccharide and clindamycin-treated bacteria. Journal of Antimicrobial Chemotherapy 12 Suppl C: 51-62. 